\title{
Urinary cell cycle arrest biomarkers and chitinase 3-like protein 1 (CHI3L1) to detect acute kidney injury in the critically ill: a post hoc laboratory analysis on the FINNAKI cohort
}

Eric A. Hoste ${ }^{1,2^{*}+}$, Suvi T. Vaara ${ }^{3 \dagger}$, Jorien De Loor ${ }^{1}$, Mikko Haapio ${ }^{4}$, Lieve Nuytinck ${ }^{5}$, Kristel Demeyere ${ }^{6}$, Ville Pettilä ${ }^{3}$, Evelyne Meyer ${ }^{6}$ and The FINNAKI Study Group

\begin{abstract}
Background: Acute kidney injury (AKI) is a frequently occurring syndrome in critically ill patients and is associated with worse outcomes. Biomarkers allow early identification and therapy of AKI which may improve outcomes. Urine chitinase 3-like protein 1 (UCHI3L1) was recently identified as a promising urinary biomarker for AKI. In this multicenter study, we evaluated the diagnostic performance for AKI stage 2 or greater of UCHI3L1 in comparison with the urinary cell cycle arrest biomarkers urinary tissue inhibitor of metalloproteinases-2 (TIMP-2).insulin-like growth factor-binding protein 7 (IGFBP7) measured by NephroCheck Risk.

Methods: Post hoc laboratory study of the prospective observational FINNAKI study. Of this cohort, we included patients with stored admission urine samples and availability of serum creatinine at day 1 of admission. Patients who already had AKI stage 2 or 3 at ICU admission were excluded. AKI was defined and staged according to the KDIGO definition and staging system. The primary endpoint was AKI stage 2 or 3 at day 1. Biomarker performance was assessed by the area under the curve of the receiver operating characteristic curve (AUC). We assessed individual performance and different combinations of urine biomarkers.
\end{abstract}

Results: Of 660 included patients, 49 (7.4\%) had AKI stages 2-3 at day 1. All urine biomarkers were increased at admission in AKI patients. All biomarkers and most combinations had AUCs $<0.700$. The combination UCHI3L1•TIMP-2 was best with a fair AUC of $0.706(0.670,0.718)$. UCHI3L1 had a positive likelihood ratio (LR) of 2.25 which was comparable to that of the NephroCheck Risk ${ }^{\circledR}$ cutoff of 2.0, while the negative LR of 0.53 was comparable to that of the NephroCheck Risk ${ }^{\circledR}$ cutoff of 0.3 .

(Continued on next page)

\footnotetext{
* Correspondence: eric.hoste@ugent.be

Eric A Hoste and Suvi T Vaara act as equivalent first authors.

${ }^{\dagger}$ Eric A. Hoste and Suvi T. Vaara contributed equally to this work.

'Intensive Care Unit, Ghent University Hospital, 2K12, Route 1280a, C.

Heymanslaan 10, 9000 Ghent, Belgium

${ }^{2}$ Research Fund-Flanders (FWO), Egmontstraat 5, 1000 Brussel, Belgium

Full list of author information is available at the end of the article
}

C C The Author(s). 2020 Open Access This article is licensed under a Creative Commons Attribution 4.0 International License, which permits use, sharing, adaptation, distribution and reproduction in any medium or format, as long as you give appropriate credit to the original author(s) and the source, provide a link to the Creative Commons licence, and indicate if changes were made. The images or other third party material in this article are included in the article's Creative Commons licence, unless indicated otherwise in a credit line to the material. If material is not included in the article's Creative Commons licence and your intended use is not permitted by statutory regulation or exceeds the permitted use, you will need to obtain permission directly from the copyright holder. To view a copy of this licence, visit http://creativecommons.org/licenses/by/4.0/ The Creative Commons Public Domain Dedication waiver (http://creativecommons.org/publicdomain/zero/1.0/) applies to the data made available in this article, unless otherwise stated in a credit line to the data. 


\begin{abstract}
(Continued from previous page)
Conclusions: We found that $\mathrm{UCH} 3 \mathrm{~L} 1$ and NephroCheck Risk ${ }^{\circledast}$ had a comparable diagnostic performance for diagnosis of AKI stage 2 or greater within a 24-h period in this multicenter FINNAKI cohort. In contrast to initial discovery and validation studies, the diagnostic performance was poor. Possible explanations for this observation are differences in patient populations, proportion of emergency admissions, proportion of functional AKI, rate of developing AKI, and observation periods for diagnosis of AKI.
\end{abstract}

Keywords: Acute kidney injury, Biological markers, Biomarkers, Chitinase, Lipocalins, Intensive care, NephroCheck

\section{Background}

Acute kidney injury (AKI) is a commonly occurring syndrome in critically ill patients admitted to the intensive care unit (ICU) and is associated with increased morbidity and mortality [1]. Recent studies indicate that the incidence of AKI in ICU patients varies between 39 and 56\% when defined by the Kidney Disease: Improving Global Outcomes (KDIGO) consensus criteria [2-4]. These criteria define AKI based upon an increase of plasma creatinine concentration $(\mathrm{Cr})$ or a period of decreased urine output (UO), and so reflect changes in glomerular filtration rate (GFR). Kidney biomarkers indicate stress or damage to the kidney tubular cells, thus giving additional information potentially at an earlier stage than $\mathrm{Cr}$ or UO [5]. This may be of importance since more early identification and stratification of therapy by the use of AKI biomarkers can improve outcomes [6,7].

At present, the 2-biomarker panel of the cell cycle arrest biomarkers urinary tissue inhibitor of metalloproteinases2 (TIMP-2)•insulin-like growth factor-binding protein 7 (IGFBP7) has shown the best predictive value for AKI in general ICU patients [5]. Given, the heterogeneous etiology of AKI and also different patients' baseline characteristics, different biomarkers may be complimentary to each other. Recently, we showed in a single-center prospective cohort study that urinary chitinase 3-like protein 1 (uCHI3L1) is a promising AKI biomarker in ICU patients when compared to urinary neutrophil gelatinaseassociated lipocalin (UNGAL) [8]. A subsequent study by our group in adult patients who underwent elective cardiac surgery demonstrated that in this specific setting, both uCHI3L1 and UNGAL showed inadequate predictive value for AKI [9].

The aim of this study was to evaluate uCHI3L1 as a biomarker for AKI in ICU patients included in the multicenter Finnish Acute Kidney Injury (FINNAKI) study and compare this to the NephroCheck Risk ${ }^{\circ}$ score, the composite of the cell cycle arrest biomarkers TIMP-2 and IGFBP7. This may provide external validation to the biomarker $\mathrm{uCHI} 3 \mathrm{~L} 1$ that showed promise in our single-center study [8].

\section{Methods}

This was a post hoc laboratory study of the prospective, observational FINNAKI study conducted in 17 Finnish intensive care units (ICUs) between September 1, 2011, and February 1, 2012 [4]. The Ethics Committee of the Department of Surgery at the Helsinki University Hospital gave a nationwide approval for the study. To include patients, we used deferred consent and as soon as possible obtained a written, informed consent. Each patient or his/her next of kin gave a written, informed consent. The study was conducted according to the Declaration of Helsinki. Reporting is according to the STROBE guidelines (suppl. data) [10].

\section{Patients}

We enrolled all patients with an emergency admission to the ICU of any duration or an elective post-surgical admission expected to last over $24 \mathrm{~h}$ in the primary study [4]. Patients were excluded if they (1) had end-stage renal disease requiring maintenance dialysis; (2) were organ donors; (3) received intermediate care, since our focus was on critically ill patients; (4) had received renal replacement therapy (RRT) while enrolled in the study during previous ICU admission; (5) were transferred from another ICU where the data collection for the study was fulfilled; or (6) were not permanently living in Finland or were unable to give consent due to insufficient language skills as informed consent needs to be given using mother tongue. From the current analysis, we further excluded patients who (1) were enrolled to the study before December 1, 2011, and did not have centrifuged urine samples; (2) did not consent for urine sampling or where no sample was taken; (3) had undergone surgery with cardiopulmonary bypass; these were excluded as $\mathrm{uCHI} 3 \mathrm{~L} 1$ proved of less value in this cohort in a previous study; (4) had already stage 2 or 3 AKI within $2 \mathrm{~h}$ of ICU admission; (5) were treated with RRT for non-renal indications, as this would lead to false positives when non-renal use of RRT is classified as AKI; or (6) did not have a blood sample taken at $24 \mathrm{~h}$ from admission and also no routine $\mathrm{Cr}$ measurement taken 12 to $25 \mathrm{~h}$ from admission. If one of these samples was present, the patient was included (Fig. 1).

\section{Sample collection}

Urine samples were collected within $2 \mathrm{~h}$ once the patient was admitted to the ICU. Additionally, blood and urine 


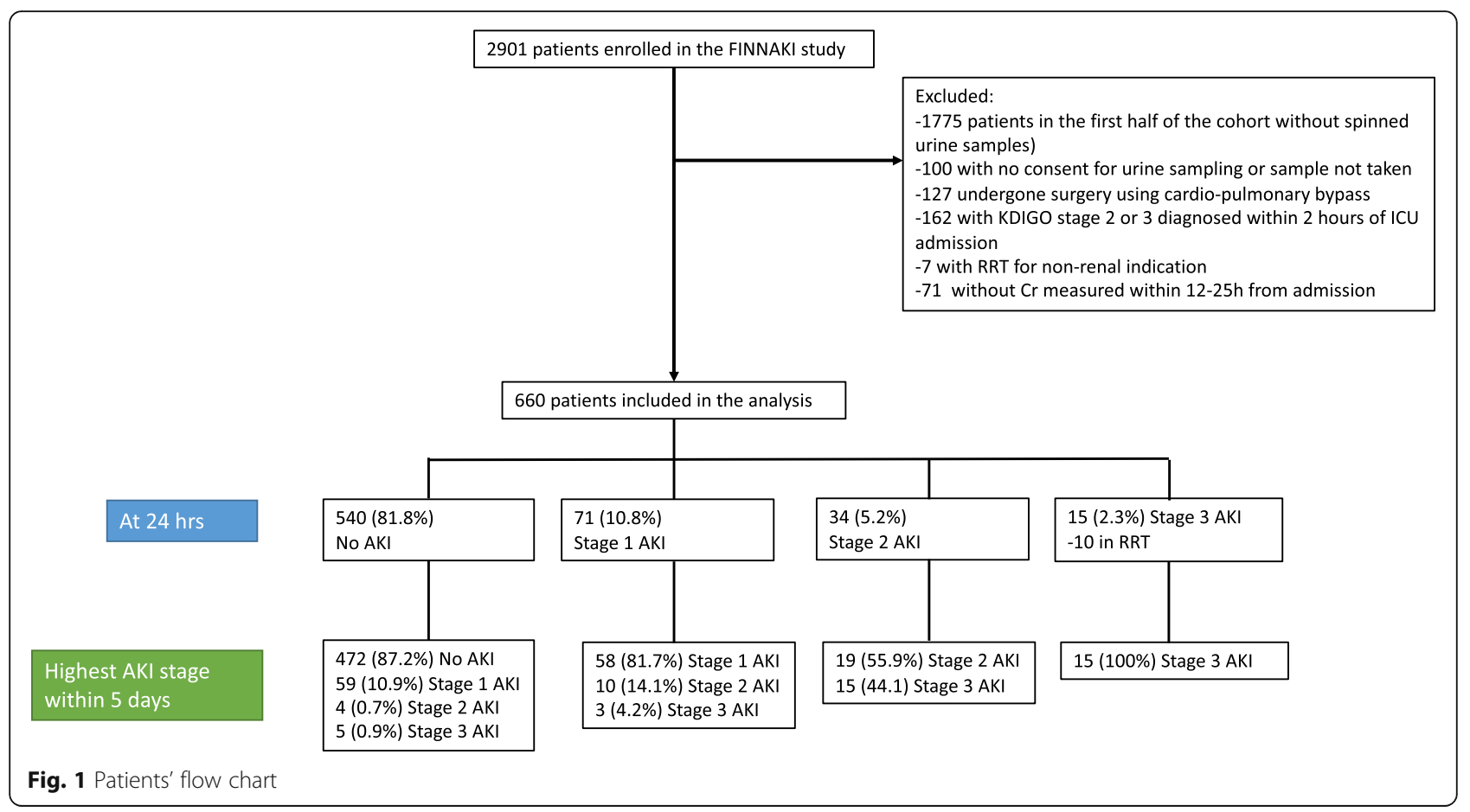

were collected $24 \mathrm{~h}$ later if the patient was still in the ICU. Urine samples were centrifuged and frozen in aliquots. Kidney biomarkers were analyzed on urine samples that were collected within $2 \mathrm{~h}$. Blood samples were collected in EDTA tubes and centrifuged, aliquoted, and frozen. Samples were kept in $-80^{\circ}$ until analyzed.

\section{Laboratory assays}

The uCHI3L1, urinary TIMP-2, urinary IGFBP7, and NephroCheck Risk ${ }^{\circ}$ analyses were performed in 2018. The laboratory analyses were performed blinded to the clinical data and the KDIGO classification. We measured the concentration of $\mathrm{uCHI}$ LL1 by a sandwich enzyme-linked immunosorbent assay (ELISA) technique (DC3L10, R\&D Systems, Minneapolis, MN, USA). With the Astute $140^{\circ}$ Meter, we measured the concentrations of urinary TIMP2, urinary IGFBP7, and NephroCheck Risk ${ }^{\circ}$ by a fluorescent immunoassay technique (NephroCheck ${ }^{\bullet}$ Test, Astute Medical, San Diego, CA, USA). Details on these laboratory analyses were recently described [9].

In addition, we also evaluated the combinations of uCHI3L1 and the individual cell cycle arrest biomarkers and the NephroCheck Risk ${ }^{\circ}$ for the prediction of AKI stage 2 or greater. Similar to the NephroCheck Risk ${ }^{\circ}$, this was done by multiplying the concentrations of individual biomarkers, e.g., uCHI3L1 conc x TIMP-2 concentration.

\section{Data collection}

We collected data on patients' baseline characteristics and risk factors for AKI with case report forms. These data were supplemented by physiological and laboratory data, disease severity scores, and ICU diagnoses from the ICU data management system via the Finnish Intensive Care Consortium database. The attending clinicians screened the patients for the presence of sepsis according to the ACCP/SCCM definition until day 5 [11]. The presence of pre-existing chronic kidney disease (CKD) was defined as GFR $<60 \mathrm{~mL} / \mathrm{min} / 1.73 \mathrm{~m}^{2}$ as mentioned in patients' medical records.

\section{Diagnosis of AKI and study endpoints}

In the FINNAKI study, we classified AKI according to the KDIGO definition on routinely measured $\mathrm{Cr}$ and hourly UO as well as RRT in the ICU. As baseline Cr, we used the most recent value obtained within a year but at least a week preceding ICU admission. If baseline $\mathrm{Cr}$ was not available and patients had no previous history of CKD, a Modification of Diet in Renal Disease (MDRD) equation-derived baseline creatinine was used, assuming a minimum GFR of $75 \mathrm{~mL} / \mathrm{min} / 1.73 \mathrm{~m}^{2}$ following the Acute Dialysis Quality Initiative (ADQI) and KDIGO recommendations [2, 12]. The study protocol did not include scheduled $\mathrm{Cr}$ measurements, and all data were observational. $\mathrm{Cr}$ was generally measured once daily in the morning lab tests. For the purpose of the current analysis, we analyzed all available plasma samples taken at $24 \mathrm{~h}$ for $\mathrm{Cr}(n=588$ patients). Additionally, 72 patients had $\mathrm{Cr}$ measured as part of the ICU lab routines within 12 to $25 \mathrm{~h}$ from ICU admission. Thus, an index $\mathrm{Cr}$ measured at least $12 \mathrm{~h}$ but not more than $25 \mathrm{~h}$ 
from admission was available from 660 patients. All these patients also had urine output recordings at least for $12 \mathrm{~h}$ and data about RRT use in the ICU. Based on these data, we formed the primary endpoint of the analysis: AKI stage 2 or 3 at $24 \mathrm{~h}$.

As a sensitivity analysis, we analyzed the biomarker performance to predict (1) AKI of any severity at $24 \mathrm{~h}$, (2) AKI of any severity at $48 \mathrm{~h}$, and (3) stage 2 or 3 AKI at $48 \mathrm{~h}$. The latest $\mathrm{Cr}$ values and $\mathrm{UO}$ recordings available up to $48 \mathrm{~h}$ from ICU admission were used to define the patient's AKI status at $48 \mathrm{~h}$. Longer time periods were not considered, since multiple events may contribute to the occurrence of AKI. If these occur after the measurement of the biomarker, there will be a negative biomarker reading. These patients will so incorrectly be classified as false negatives: negative biomarker and still occurrence of AKI.

\section{Statistical analysis}

We report the non-normally distributed continuous data as median with interquartile range (IQR) and categorical data with count and percentage. We compared continuous data using Mann-Whitney $U$ test and categorical data with Fisher's exact test or chisquare test where appropriate. We assessed the predictive ability of the biomarkers and combinations for the primary endpoint by calculating the area under the receiver-operator characteristic curve (AUC-ROC) and compared these according to the method of DeLong et al. and with the calculation of binomial exact 95\% confidence intervals [13]. For uCHI3L1 and the combination of this biomarker with the other biomarkers, we assessed a cutoff based on the Youden index [14]. We considered a two-sided $p$ value less than 0.05 as significant and did not correct for multiple comparisons.

We pre-defined the AUC as follows: excellent, $0.900 \leq$ AUC-ROC $\leq 1 ;$ good, $0.800 \leq$ AUC-ROC $\leq 0.899$; fair, $0.700 \leq \mathrm{AUC}-\mathrm{ROC} \leq 0.799 ;$ poor, $0.600 \leq \mathrm{AUC}-\mathrm{ROC} \leq$ 0.699; and failed when AUC-ROC < 0.600 [15].

Analyses were conducted using SPSS Statistics 23.0 for Microsoft and 24.0 for Mac (IBM, Armonk, NY), MedCalc Statistical Software version 19.0.4 (MedCalc Software bvba, Ostend, Belgium), and RStudio 1.1.456 for Mac.

\section{Results}

A total of 660 patients were included in this study (Fig. 1). Of these, 120 (18.2\%) patients had AKI at time $24 \mathrm{~h}$ after ICU admission. Their baseline characteristics are provided in Table 1 . Of these patients, $96 \%$ were emergency admissions, $70 \%$ received mechanical ventilation, and $54.2 \%$ of them were administered norepinephrine. Altogether, 21 patients (3.2\%) had AKI stage 1 diagnosed within $2 \mathrm{~h}$ of ICU admission. Of these, 5 patients had AKI stage 2 or 3 at $24 \mathrm{~h}$ and 4 at $48 \mathrm{~h}$.

KDIGO AKI stage 2-3 criteria were met by 49 patients (7.4\%) at $24 \mathrm{~h}$ (i.e., the primary endpoint). Of those 49 , AKI criteria were met by 27 (55.1\%) using $\mathrm{Cr}$ criteria and in 29 (59.1\%) using UO criteria; 10 patients (20.4\%) were treated with RRT within the first $24 \mathrm{~h}$ after ICU admission. AKI was diagnosed by $\mathrm{Cr}$ criteria only in 15 patients (30.6\%) and UO criteria only in 17 patients (34.7\%), 12 patients (24.5\%) met both $\mathrm{Cr}$ and UO criteria, and in 5 patients, AKI was diagnosed on use of RRT only.

Patients with AKI stage 2 or greater were older and had higher baseline creatinine compared to patients with AKI stages $0-1$. AKI stage $2-3$ patients had more risk factors for AKI such as hypovolemia, massive transfusion, acute liver failure, cardiogenic shock, administration of hydroxyethyl starch or peptidoglycan antibiotics, and emergency or surgical admission. Finally, AKI stage 2-3 patients had higher SAPS II and SOFA scores and received more often mechanical ventilation and/or norepinephrine.

\section{Urinary biomarkers for early diagnosis of AKI stage 2 or 3 at $24 \mathrm{~h}$}

Patients with AKI stage 2 or greater at $24 \mathrm{~h}$ had higher concentrations for all urinary biomarkers and for the different combinations thereof measured at ICU admission (Table 2).

The AUC-ROCs for AKI stage 2 or greater at $24 \mathrm{~h}$ were poor $(<0.700)$ for all biomarkers and their combinations, except for the combination uCHI3L1•TIMP-2 with a fair AUC-ROC of 0.706 (Fig. 2). This AUC-ROC was not statistically significantly higher than those of either uCHI3L1 or NephroCheck Risk ${ }^{\circledR}$ alone.

Based on a Youden analysis, the best cutoff for uCHI3L1 was assessed, and these sensitivity and specificity values were found to be in between those of the NephroCheck Risk ${ }^{\circledR}$ cutoff values of 0.3 and 2.0 (Table 3) [16]. The positive likelihood ratio (LR) of AKI stage 2 or greater for $\mathrm{uCHI}$ LL1 was comparable to that of the NephroCheck Risk ${ }^{\circledR} 2.0$ cutoff, while the negative LR was comparable to that of the NephroCheck Risk ${ }^{\otimes} 0.3$ cutoff (Table 3). Combining uCHI3L1 either with IGFBP7 or with the NephroCheck Risk $^{\bullet}$ resulted in an increase of the specificity, a decrease of sensitivity, and the highest positive LRs.

\section{Sensitivity analyses}

The AUC-ROCs for AKI of any severity of AKI at $24 \mathrm{~h}$ for all biomarkers and their combinations were poor $(<0.700)$. Sensitivity, specificity, and positive and negative likelihood ratios were corresponding to that of the primary endpoint (Additional file table 1). The results regarding AKI of any 
Table 1 Baseline characteristics of patients

\begin{tabular}{|c|c|c|c|c|c|}
\hline & $\begin{array}{l}\text { Data } \\
\text { available }\end{array}$ & All patients & $\begin{array}{l}\text { AKl stage } 2 \text { or } 3 \text { at } 24 \mathrm{~h} \\
(n=49)\end{array}$ & $\begin{array}{l}\text { AKl stage } 0 \text { or } 1 \text { at } 24 \mathrm{~h} \\
(n=611)\end{array}$ & $p$ value \\
\hline Age (years) & 660 & 64 [53-73] & 68 [57-77] & 64 [52-73] & 0.038 \\
\hline Male sex & 660 & $410 / 660(62.1 \%)$ & $35 / 49(71.4 \%)$ & $375 / 611(61.4 \%)$ & 0.172 \\
\hline BMI $\left(\mathrm{kg} / \mathrm{m}^{2}\right)$ & 658 & $26.1[23.4-29.4]$ & $26.3[24.4-30.9]$ & $26.1[23.4-29.4]$ & 0.275 \\
\hline Baseline creatinine ( $\mu \mathrm{mol} / \mathrm{L})$ & 393 & 75 [61-95] & $81[68-107]$ & 75 [60-93] & 0.028 \\
\hline $\begin{array}{l}\text { Baseline } \mathrm{Cr} \text { with missing values imputed* } \\
(\mu \mathrm{mol} / \mathrm{L})\end{array}$ & 660 & 82 [69-95] & 90 [74-99] & 81 [69-95] & 0.058 \\
\hline Diabetes mellitus & 660 & $139 / 660(21.2 \%)$ & $11 / 49(22.4 \%)$ & 128/611 (20.9\%) & 0.855 \\
\hline Arteriosclerosis & 650 & $90 / 650(13.6 \%)$ & $10 / 48(20.8 \%)$ & 80/602 (13.3\%) & 0.189 \\
\hline CKD & 659 & $41 / 659(6.2 \%)$ & 4/49 (8.2\%) & $37 / 610(6.1 \%)$ & 0.535 \\
\hline Chronic liver disease & 654 & 20/654 (3.0\%) & $1 / 49(2.0 \%)$ & 19/605 (3.1\%) & $>0.999$ \\
\hline Hypertension & 652 & $304 / 652(46.1 \%)$ & $24 / 49(49.0 \%)$ & 280/603 (46.4\%) & 0.767 \\
\hline Systolic heart failure & 651 & $61 / 651$ (9.2\%) & $6 / 48(12.5 \%)$ & $55 / 603$ (9.1\%) & 0.438 \\
\hline Chronic obstructive pulmonary disease & 656 & 73/656 (11.1\%) & $7 / 49(14.3 \%)$ & 66/607 (10.9\%) & 0.477 \\
\hline \multicolumn{6}{|l|}{ Pre-ICU AKI risk factors** } \\
\hline Sepsis & 660 & $144 / 660(21.8 \%)$ & $14 / 49(28.6 \%)$ & 130/611 (21.3\%) & 0.279 \\
\hline Hypovolemia & 657 & $179 / 657(27.1 \%)$ & 23/49 (46.9\%) & $156 / 608(25.7 \%)$ & 0.002 \\
\hline Cardiopulmonary resuscitation & 660 & $86 / 660(13.0 \%)$ & $6 / 49(12.2 \%)$ & 80/611 (13.1\%) & $>0.999$ \\
\hline Massive transfusion & 660 & $16 / 660(2.4 \%)$ & $4 / 49(8.2 \%)$ & 12/611 (2.0\%) & 0.025 \\
\hline Acute liver failure & 660 & $10 / 660(1.5 \%)$ & $3 / 49(6.1 \%)$ & $7 / 611(1.1 \%)$ & 0.032 \\
\hline Cardiogenic shock & 660 & $19 / 660(2.9 \%)$ & $7 / 49(14.3 \%)$ & $12 / 611(2.0 \%)$ & $<0.001$ \\
\hline Radiocontrast & 657 & 189/657 (28.6\%) & $14 / 48(29.2 \%)$ & $175 / 609(28.7 \%)$ & $>0.999$ \\
\hline Diuretics & 639 & 190/639 (28.8\%) & $17 / 47(36.25 \%)$ & 173/592 (29.2\%) & 0.323 \\
\hline $\begin{array}{l}\text { Angiotensin converting enzyme inhibitor } \\
\text { or angiotensin receptor blocker }\end{array}$ & 645 & $145 / 645(22.5 \%)$ & 13/48 (27.1\%) & 132/597 (22.1\%) & 0.472 \\
\hline Non-steroidal anti-inflammatory drug & 622 & $61 / 622(9.8 \%)$ & $5 / 45(11.1 \%)$ & $56 / 577$ (9.7\%) & 0.793 \\
\hline Hydroxyethyl starch & 645 & $78 / 645$ (12.1\%) & $17 / 49(34.7 \%)$ & 61/596 (10.2\%) & $<0.001$ \\
\hline Peptidoglycan antibiotic & 659 & $28 / 659(4.2 \%)$ & $5 / 49(10.2 \%)$ & 23/610 (3.8\%) & 0.049 \\
\hline Emergency admission & 660 & 635/660 (96.2\%) & 44/49 (89.8\%) & $591 / 611(96.7 \%)$ & 0.031 \\
\hline Surgical admission & 660 & $191 / 660(29.1 \%)$ & $22 / 49(44.9 \%)$ & $170 / 611(27.8 \%)$ & 0.014 \\
\hline \multicolumn{6}{|l|}{ Admitted from } \\
\hline Operation room or recovery & 660 & $177 / 660(26.8 \%)$ & $22 / 49(44.9 \%)$ & 155/611 (25.4\%) & 0.004 \\
\hline Emergency department & 660 & $272 / 660(41.2 \%)$ & $8 / 49(16.3 \%)$ & 264/611 (43.2\%) & $<0.001$ \\
\hline Ward & 660 & $131 / 660(19.8 \%)$ & 15/49 (30.6\%) & 116/611 (19.0\%) & 0.062 \\
\hline Other ICU/high-dependency unit/others & 660 & $80 / 660(12.1 \%)$ & $4 / 49(8.2 \%)$ & 76/611 (12.4\%) & 0.497 \\
\hline SAPS ॥ (24 h) & 660 & 38 [29-49] & 52 [37-63] & 37 [28-48] & $<0.001$ \\
\hline SOFA (24 h) & 660 & $7[4-9]$ & $10[8-13]$ & 6 [4-9] & $<0.001$ \\
\hline Mechanical ventilation during ICU stay & 660 & $462 / 660(70.0 \%)$ & $43 / 49(87.8 \%)$ & $419 / 611(68.6 \%)$ & 0.003 \\
\hline Norepinephrine (within 24 h) & 660 & $358 / 660(54.2 \%)$ & $43 / 49(87.8 \%)$ & $315 / 611(51.6 \%)$ & $<0.001$ \\
\hline
\end{tabular}

*MDRD equation assuming GRF $\geq 75 \mathrm{~mL} / \mathrm{min} / 1.73 \mathrm{~m}^{2}$. Imputed for 16 patients with endpoint+ and 251 with endpoint**Pre-ICU AKI risk factors if present in $48 \mathrm{~h}$ preceding ICU admission

severity at $48 \mathrm{~h}$ (Additional file Table 2) and stage 2 or 3 AKI at $48 \mathrm{~h}$ (Additional file table 3 ) corroborated that of the primary endpoint.

\section{Discussion}

In this multicenter validation study, we found that uCHI3L1 was markedly increased in general ICU patients who developed AKI stage 2 or 3 within a 24-h 
period after their ICU admission. Urine CHI3L1 had a comparable diagnostic performance to TIMP-2.IGFBP7. Combining uCHI3L1 with the NephroCheck Risk ${ }^{\circ}$ or IGFBP7 resulted in a less sensitive but a more specific test with the highest positive LRs (i.e., 1.69 to 2.75). However, LRs of this magnitude will generate a little effect on posttest disease probability in clinical practice [15].

This study and previous studies on uCHI3L1 have demonstrated its use as a biomarker for diagnosis of AKI, and this with comparable performance to UNGAL and NephroCheck Risk ${ }^{\circ}$ [8, 9, 17-19]. CHI3L1 may also provide mechanistic insights in injury and repair mechanisms in the kidney. Kidney stress or damage will promote that macrophages in the kidney secrete CHI3L1 [17]. Biological effects of CHI3L1 include control of cell death, inflammation, and remodeling in renal epithelial cells and macrophages [20-22].

Notably, the diagnostic performance for AKI stage 2 or 3 within a 24-h period was markedly lower when compared to earlier validation studies for $\mathrm{uCHI} 3 \mathrm{~L} 1$ and NephroCheck Risk ${ }^{\circ}$ [7, 8]. Indeed, we showed in a single-center general ICU cohort that for diagnosing AKI stage 2 or greater, uCHI3L1 had an AUC-ROC of 0.784 at $12 \mathrm{~h}$ and 0.721 at $24 \mathrm{~h}$ [8]. In the Sapphire study, the NephroCheck Risk ${ }^{\bullet}$ which combines the two biomarker urinary proteins TIMP-2 and IGFBP7 had an AUC-ROC of 0.80 at $12 \mathrm{~h}$ [5]. How should the current FINNAKI study data be interpreted? First, as AKI is a syndrome with marked heterogeneity, it is very likely that unmeasured confounders play a role in differences in the diagnostic performance of kidney biomarkers. While all 3 studies included patients from ICUs from developed countries in an apparently similar setting and with comparable age, comorbidities, and risk factors, there may have been differences in the baseline characteristics of patients. This hypothesis can be illustrated by the differences in the occurrence of AKI stage 2 or greater at $24 \mathrm{~h}$. In the uCHI3L1 validation study, we found that $5 \%$ of patients developed AKI stage 2 or greater at $24 \mathrm{~h}$ compared to $7.4 \%$ in this study and to $14 \%$ within $12 \mathrm{~h}$ in the Sapphire study. A comparative overview of the baseline characteristics of these three studies (FINNAKI-CHI3L1 versus BAKI-I and Sapphire) is provided in Table 4. Strikingly, age, diabetes, baseline $\mathrm{Cr}$, severity of illness, and type of ICU patients are different between studies. Apparently, a marked proportion of patients already have developed AKI stage 2 or greater when admitted to the ICU. Thus, potential interesting endpoints for future biomarker research would be the non-resolution of AKI. Second, the timing of diagnosis may explain the differences in AUC. Here, we measured AKI occurrence within a 24-h period after admission, a period during which ICU patients typically experience a complicated and eventful clinical course. Several new events may occur during this period resulting in injury or stress to the kidneys. A biomarker reading before these events occur will inevitably underestimate or miss this. Others have also reported lower AUCs for the NephroCheck Risk $^{\circ}$ when a longer detection period was used [23-25]. Third, the risk of progression to AKI stage 2 from baseline no AKI may be lower compared to baseline AKI stage 1. Therefore, a large proportion of no AKI patients at the time of inclusion may lower the diagnostic performance compared to studies in which a higher number of patients already had AKI stage 1 at inclusion. In our study, the majority of patients had no AKI (96.2\%) at the time of inclusion. In Sapphire and BAKI-I, the number of patients who already had AKI stage 1 at the time of inclusion was not reported. Fourth, AKI is a syndrome with heterogeneous baseline characteristics. However, we consider our study population and findings representative to usual care in developed countries given the nationwide multicenter design, the internationally high standard of intensive care in Finland, consecutive inclusion of all patients with a deferred consent policy, a low rate of patients excluded without

Table 2 Biomarker levels. Median [IQR] biomarker concentrations in patients according to positive or negative primary endpoint (KDIGO stage 2 or $3 \mathrm{AKI}$ at $24 \mathrm{~h}$ )

\begin{tabular}{|c|c|c|c|}
\hline & AKl stage 2 or 3 at $24 \mathrm{~h}(n=49)$ & AKI stage 0 or 1 at $24 \mathrm{~h}(n=611)$ & $p$ value \\
\hline uCHI3L1 (ng/mL) & $3.92[0.12-12.45]$ & $0.44[0.12-2.42]$ & $<0.001$ \\
\hline TIMP-2 (ng/mL) & $6.40[3.15-10.15]$ & $3.40[1.80-6.10]$ & $<0.001$ \\
\hline IGFBP7 (ng/mL) & $109.0[46.9-300.9]$ & $64.3[32.4-128.9]$ & 0.01 \\
\hline NephroCheck Risk ${ }^{\circledast}(\mathrm{ng} / \mathrm{mL})^{2} / 1000$ & $0.96[0.19-2.64]$ & $0.22[0.06-0.85]$ & $<0.001$ \\
\hline NephroCheck Risk ${ }^{\oplus}>0.3$ and $\leq 2.0(\mathrm{ng} / \mathrm{mL})^{2} / 1000$ & $22 / 49(44.9 \%)$ & 190/611 (31.1\%) & $<0.001$ \\
\hline NephroCheck Risk ${ }^{\oplus}>2.0(\mathrm{ng} / \mathrm{mL})^{2} / 1000$ & $14 / 49(28.6 \%)$ & $75 / 611(12.3 \%)$ & \\
\hline uCHI3L1·TIMP-2 (ng/mL) $)^{2}$ & $19.18[1.34-113.50]$ & $1.24[0.27-13.95]$ & $<0.001$ \\
\hline uCHI3L1 $\cdot \mid \mathrm{GFB} 7(\mathrm{ng} / \mathrm{mL})^{2}$ & 199.6 [19.4-2932.9] & $20.9[5.1-221.7]$ & $<0.001$ \\
\hline uCHI3L1•NephroCheck Risk ${ }^{\circledast}(\mathrm{ng} / \mathrm{mL})^{3} / 1000$ & $2.04[0.11-28.13]$ & $0.09[0.01-1.31]$ & $<0.001$ \\
\hline
\end{tabular}




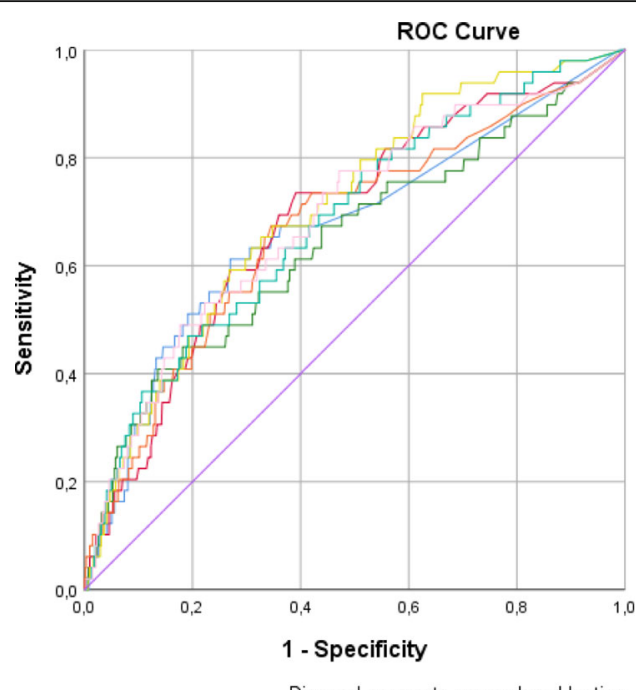

$$
\begin{gathered}
\begin{array}{c}
\text { Source of the } \\
\text { Curve }
\end{array} \\
\text { CH3L1 } \\
\text { - TIMP } 2 \\
\text { - IGFBE } 7 \\
\text { - NC_index } \\
\text { CHIS1_X_TIMP2 } \\
\text { - CHI3L1_X_IGFBP7 } \\
\text { CHI3L1_X_NCindex } \\
\text { - Reference Line }
\end{gathered}
$$

\begin{tabular}{|c|c|c|}
\hline Variable & AUC-ROC & $95 \% \mathrm{Cl}$ \\
\hline uCHI3L1 & 0.670 & $0.632,0.706$ \\
\hline TIMP-2 & 0.685 & $0.648,0.720$ \\
\hline IGFBP7 & 0.643 & $0.605,0.680$ \\
\hline NephroCheck Risk ${ }^{\circledast}$ & 0.671 & $0.633,0.706$ \\
\hline uCH3L1・TIMP-2 & 0.706 & $0.670,0.741$ \\
\hline uCHI3L1 • IGFBP7 & 0.683 & $0.646,0.718$ \\
\hline uCH3L1・ NephroCheck Risk ${ }^{\circledast}$ & 0.689 & $0.652,0.724$ \\
\hline
\end{tabular}

Diagonal segments are produced by ties.

$95 \% \mathrm{Cl}$

Fig. 2 ROC curves for biomarkers for the primary endpoint: AKI stage 2 or 3 at $24 \mathrm{~h}(n=49$ positive) informed consent, and the exclusion of patients with AKI already at ICU admission from this analysis [26].

\section{Strengths and limitations}

Our study has several strengths such as the multicenter study design with a diagnosis of AKI according to the full

\begin{tabular}{|c|c|c|c|c|c|}
\hline Biomarker & Cutoff value & Sensitivity & Specificity & Positive LR & Negative LR \\
\hline uCHI3L1 (ng/mL) & $>2.1$ & $61.2 \%(46.2,74.8)$ & $72.8 \%(69.1,76.3)$ & $2.25(1.74,2.92)$ & $0.53(0.37,0.76)$ \\
\hline NephroCheck Risk ${ }^{\circledast}(\mathrm{ng} / \mathrm{mL})^{2} / 1000$ & $>0.3$ & $73.5 \%(58.9,85.1)$ & $56.6 \%(52.6,60.6)$ & $1.69(1.34,2.05)$ & $0.47(0.29,0.75)$ \\
\hline NephroCheck Risk ${ }^{\circledast}(\mathrm{ng} / \mathrm{mL})^{2} / 1000$ & $>2.0$ & $28.6 \%(16.6,43.3)$ & $87.7 \%(84.9,90.2)$ & $2.33(1.43,3.80)$ & $0.81(0.68,0.97)$ \\
\hline uCHI3L1·TIMP-2 (ng/mL) $)^{2}$ & $>5.5$ & $65.3 \%(50.4,78.3)$ & $67.3 \%(63.4,71.0)$ & $2.00(1.58,2.52)$ & $0.52(0.35,0.76)$ \\
\hline uCHI3L1•|GFBP7 $(\mathrm{ng} / \mathrm{mL})^{2}$ & $>459.8$ & $46.9 \%(32.5,61.7)$ & $80.7 \%(77.3,83.7)$ & $2.43(1.73,3.41)$ & $0.66(0.50,0.86)$ \\
\hline uCH3L1• NephroCheck Risk ${ }^{\oplus}(\mathrm{ng} / \mathrm{mL})^{3} / 1000$ & $>3.3$ & $48.9 \%(34.4,63.7)$ & $82.2 \%(78.9,85.1)$ & $2.75(1.97,3.83)$ & $0.62(0.47,0.82)$ \\
\hline
\end{tabular}
KDIGO definition and staging system in a large cohort of
ICU patients. As such, this is the first external validation study of uCHI3L1 in general ICU patients compared with the NephroCheck Risk ${ }^{\circ}$, the current best-performing AKI biomarker for early diagnosis and kidney stress. Finally, we also assessed the diagnostic performance of uCHI3L1 in combination with the NephroCheck Risk ${ }^{\circ}$ test and its individual elements. Therefore, we believe the results of

Table 3 Diagnostic performance of biomarkers and biomarker combinations for AKI defined by KDIGO occurring at $24 \mathrm{~h}$ 
Table 4 Comparison of three AKI biomarker study characteristics

\begin{tabular}{|c|c|c|c|}
\hline & Sapphire [5] & BAKI-I [8] & FINNAKI-CHI3L1 (present study) \\
\hline$n$ & 728 & 181 & 660 \\
\hline Biomarker studied & TIMP-2•|GFBP7 & CHI3L1 & $\begin{array}{l}\text { CHI3L1 } \\
\text { TIMP-2•IGFBP7 }\end{array}$ \\
\hline Centers & Multi & Single & Multi \\
\hline Age (years) & $64(53,73)$ & $60(51,70)$ & $64(53,73)$ \\
\hline Male gender (\%) & 62 & 63 & 62 \\
\hline Baseline $\mathrm{Cr}(\mu \mathrm{mol} / \mathrm{L})$ & 80 & 58 & 82 \\
\hline Diabetes (\%) & 29 & 7.2 & 21.2 \\
\hline SAPS ॥ & NA & NA & $38(29,49)$ \\
\hline APACHE III & $69(51,90)$ & NA & NA \\
\hline SOFA & NA & $9(7,11)$ & $7(4,9)$ \\
\hline Emergency department & NA & $41.4 \%$ & $41.2 \%$ \\
\hline Medical ICU admission (\%) & 31.0 & 59.7 & 70.9 \\
\hline AKI stages $2-3<12$ h (\%) & 14.0 & 3.3 & NA \\
\hline AKI stages $2-3<24$ h (\%) & NA & 4.9 & 7.4 \\
\hline AUC-ROC for AKI stages $2-3<12 \mathrm{~h}$ & 0.80 & 0.79 & NA \\
\hline AUC-ROC for AKI stages $2-3<24 \mathrm{~h}$ & NA & 0.72 & $\begin{array}{l}\text { uCHI3L1, } 0.67 \\
\text { NephroCheck, } 0.67\end{array}$ \\
\hline
\end{tabular}

this study are generalizable to patients admitted to ICUs in developed countries in similar settings.

Our study has also some limitations to be considered. First, we were able to include only 660 patients from the full cohort $(n=2901)$, because only a proportion of the full FINNAKI multicenter cohort had centrifuged frozen urine samples available. However, we consider possible bias as limited since these 660 patients represented the last consecutively admitted patients of the study. Second, plasma $\mathrm{Cr}$ was not sampled exactly at $24 \mathrm{~h}$, but rather within a 12- to 25-h time frame. Third, although unlikely, we cannot exclude that pre-analytical issues may have resulted in false-negative biomarker measurements. For instance, despite deep-frozen storage at $-80^{\circ} \mathrm{C}$, the 7 -year time delay between sample collection and analysis may have caused some protein degradation resulting in decreased detection of biomarkers. Fourth, patients with AKI stage 2 or greater were more severely ill, had higher baseline $\mathrm{Cr}$, and more patients had pre-ICU risk factors. CHI3L1, TIMP-2, and IGFBP7 are mediators that are also elevated in the plasma in acute and chronic diseases [27-34]. Johnson and Zager demonstrated that TIMP-2 and IGFBP7 are filtered by the glomeruli [35]. Given the low molecular weight of $39-40 \mathrm{kDa}$, also CHI3L1 may be filtered by the glomeruli. In summary, we cannot exclude that systemic TIMP-2, IGFBP7, and CHI3L1 entered the urine by glomerular filtration and so impacted on the diagnostic performance. Fifth, serial measurement of biomarkers could have provided deeper insights into the biomarker signals.

\section{Conclusions}

We found that $\mathrm{uCHI} 3 \mathrm{~L} 1$ and NephroCheck Risk ${ }^{\ominus}$ had a comparable diagnostic performance for diagnosis of AKI stage 2 or greater within a 24-h period in this multicenter FINNAKI cohort. In contrast to initial discovery and validation studies, the diagnostic performance was poor. Possible explanations for this observation were differences in patient populations, proportion of emergency admissions, proportion of functional AKI, rate of developing AKI, and observation periods for diagnosis of AKI. Our findings warrant additional multicenter validation studies for these biomarkers using consecutive critically ill patients and a scrutinized evaluation of additional clinical value before their wider implementation in clinical practice.

\section{Supplementary information}

Supplementary information accompanies this paper at https://doi.org/10. 1186/s13054-020-02867-W.

Additional file 1: Table S1. Diagnostic performance of biomarkers and biomarker combinations for any stage of AKI defined by KDIGO occurring at 24 hours ( $n=120,18.2 \%$ ). Table S2. Diagnostic performance of biomarkers and biomarker combinations for any stage of AKI defined by KDIGO occurring at 48 hours ( $n=88,13.3 \%$ ). Table S3. Diagnostic performance of biomarkers and biomarker combinations for stage 2 or 3 AKI defined by KDIGO occurring at 48 hours $(n=45,6.8 \%)$.

\section{Abbreviations}

AKI: Acute kidney injury; ACCP/SCCM: American College Chest Physicians/ Society of Critical Care Medicine; ADQI: Acute Dialysis Quality Initiative; AUCROC: Area under the curve of the receiver operating characteristic curve; BMI: Body mass index; CKD: Chronic kidney disease; Cr: Plasma creatinine 
concentration; ELISA: Enzyme-linked immunosorbent assay; FINNAKI: Finnish Acute Kidney Injury; GFR: Glomerular filtration rate; ICU: Intensive care unit; IGFBP7: Insulin-like growth factor-binding protein 7; IQR: Interquartile range; KDIGO: Kidney Disease: Improving Global Outcomes; LR: Likelihood ratio; MDRD: Modification of Diet in Renal Disease; NA: Not available; RRT: Renal replacement therapy; SAPS II: Simplified Acute Physiology Score II score; SOFA: Sequential Organ Failure Assessment score; TIMP-2: Tissue inhibitor of metalloProteinases-2; UCHI3L1: Urinary chitinase 3-like protein 1;

UNGAL: Urinary neutrophil gelatinase-associated lipocalin; UO: Urine output

\section{Acknowledgements}

Our special thanks to the FINNAKI investigators for including the patients into the FINNAKI study and allowing this specific analysis. We want to thank the research coordinators Sari Sutinen and Leena Pettilä who handled the FINNAKI urine samples and shipped them to Belgium for analysis, and to Astrid Thys for measuring UCHI3L1 and NephroCheck Risk ${ }^{\oplus}$. Patent application on CHI3L1was facilitated by Dr. Piet De Vos and Dr. Philippe Jacobs of the IP and Licensing Technology Transfer Office of Ghent University Tech Transfer.

The FINNAKI study group:

Central Finland Central Hospital: Raili Laru-Sompa, Anni Pulkkinen, Minna Saar elainen, Mikko Reilama, Sinikka Tolmunen, Ulla Rantalainen, and Marja Miettinen. East Savo Central Hospital: Markku Suvela, Katrine Pesola, Pekka Saastamoinen, and Sirpa Kauppinen. Helsinki University Hospital: Ville Pettilä, Kirsi-Maija Kaukonen, Anna-Maija Korhonen, Sara Nisula, Suvi Vaara, Raili Suojaranta-Ylinen, Leena Mildh, Mikko Haapio, Laura Nurminen, Sari Sutinen, Leena Pettilä, Helinä Laitinen, Heidi Syrjä, Kirsi Henttonen, Elina Lappi, and Hillevi Boman. Jorvi Central Hospital: Tero Varpula, Päivi Porkka, Mirka Sivula, Mira Rahkonen, Anne Tsurkka, Taina Nieminen, and Niina Pirttinen. KantaHäme Central hospital: Ari Alaspää, Ville Salanto, Hanna Juntunen, and Teija Sanisalo. Kuopio University Hospital: Ilkka Parviainen, Ari Uusaro, Esko Ruokonen, Stepani Bendel, Niina Rissanen, Maarit Lång, Sari Rahikainen, Saija Rissanen, Merja Ahonen, Elina Halonen, and Eija Vaskelainen. Lapland Central Hospital: Meri Pouk-kanen, Esa Lintula, and Sirpa Suominen. Länsi-Pohja Central Hospital: Jorma Heikki-nen, Timo Lavander, Kirsi Heinonen, and AnneMari Juopperi. Middle Ostrobothnia Central Hospital: Tadeusz Kaminski, Fiia Gäddnäs, Tuija Kuusela, and Jane Roiko. North Karelia Central Hospital: Sari Karlsson, Matti Reinikainen, Tero Surakka, Helena Jyrkönen, Tanja Eiserbeck, and Jaana Kallinen. Oulu University Hospital: Tero Ala-Kokko, Jouko Laurila, and Sinikka Sälkiö. Satakunta Hospital District: Vesa Lund, Päivi Tuominen, Pauliina Perkola, Riikka Tuominen, Marika Hietaranta, and Satu Johansson. South Karelia Central Hospital: Seppo Hovilehto, Anne Kirsi, Pekka Tiainen, Tuija Myllärinen, Pirjo Leino, and Anne Toropainen. Tampere University Hospital: Anne Kuitunen, Jyrki Tenhunen, Ilona Leppänen, Markus Levoranta, Sanna Hoppu, Jukka Sauranen, Atte Kukkurainen, Samuli Kortelainen, and Simo Varila. Turku University Hospital: Outi Inkinen, Niina Koivuviita, Jutta Kotamäki, and Anu Laine. Vaasa Central Hospital: Simo-Pekka Koivisto, Raku Hautamäki, and Maria Skinnar.

\section{Authors' contributions}

EAH: study design, analysis, first draft, and final draft. STV: study design, analysis, drafting of the manuscript. JDL: study design and drafting of the manuscript. MH: FINNAKI study design and final draft of the manuscript. LN: study design and final draft of the manuscript. KM: analysis and final draft of the manuscript. EM: study design, analysis, and drafting of the manuscript. VP: study design, analysis, and drafting of the manuscript. The authors read and approved the final manuscript.

\section{Funding}

This study was funded by the Industrial Research Fund from Ghent University (IOF) (F2016/IOF-ConcepTT/372).

\section{Availability of data and materials}

The dataset supporting the conclusions of this article is available from the corresponding author on reasonable request.

\section{Ethics approval and consent to participate}

The Ethics Committee of the Department of Surgery at the Helsinki University Hospital gave nationwide approval for the study and for the use of deferred consent with written, informed consent obtained as soon as possible (decision number 18/13/03/02/2010). Each patient or his/her next of kin gave a written, informed consent. The study was conducted according to the Declaration of Helsinki.

\section{Consent for publication}

Not applicable

\section{Competing interests}

Grants: Author JDL has received a predoctoral grant from the Research Foundation-Flanders (FWO). Author EAJH has received a postdoctoral grant from the Research Foundation-Flanders (FWO) and received speakers fee/ travel grant from Sopachem, Astute Medical, Alexion, and AM-Pharma. STV has received a Fellowship Grant from the Sigrid Juselius Foundation and funding for Clinical Researchers (317061) from the Academy of Finland.

\section{Author details}

${ }^{1}$ Intensive Care Unit, Ghent University Hospital, 2K12, Route 1280a, C. Heymanslaan 10, 9000 Ghent, Belgium. ${ }^{2}$ Research Fund-Flanders (FWO), Egmontstraat 5, 1000 Brussel, Belgium. ${ }^{3}$ Division of Intensive Care Medicine, Department of Anaesthesiology, Intensive Care and Pain Medicine, University of Helsinki and Helsinki University Hospital, Box 340, 00029 Helsinki, Finland. ${ }^{4}$ Division of Nephrology, Abdominal Center, University of Helsinki and Helsinki University Hospital, Box 340, FI-00029 HUS Helsinki, Finland. ${ }^{5}$ Faculty of Medicine and Health Sciences, Health Innovation and Research Institute of the Ghent University Hospital (UZ Gent) (HIRUZ) Ghent University Hospital, C. Heymanslaan 10, 9000 Ghent, Belgium. ' Department of Pharmacology, Toxicology and Biochemistry, Laboratory of Biochemistry, Faculty of Veterinary Medicine, Ghent University, Salisburylaan 133, 9820 Merelbeke, Belgium.

Received: 20 December 2019 Accepted: 31 March 2020

Published online: 10 April 2020

\section{References}

1. Hoste EAJ, Kellum JA, Selby NM, Zarbock A, Palevsky PM, Bagshaw SM, Goldstein SL, Cerda J, Chawla LS. Global epidemiology and outcomes of acute kidney injury. Nat Rev Nephrol. 2018;14(10):607-25.

2. Kidney Disease: Improving Global Outcomes (KDIGO) Acute Kidney Injury Work Group. KDIGO Clinical Practice Guideline for Acute Kidney Injury. Kidney Inter Suppl. 2012;2:1-138.

3. Hoste EA, Bagshaw SM, Bellomo R, Cely CM, Colman R, Cruz DN, Edipidis K, Forni LG, Gomersall CD, Govil D, et al. Epidemiology of acute kidney injury in critically ill patients: the multinational AKI-EPI study. Intensive Care Med. 2015;41(8):1411-23.

4. Nisula S, Kaukonen KM, Vaara ST, Korhonen AM, Poukkanen M, Karlsson S, Haapio M, Inkinen O, Parviainen I, Suojaranta-Ylinen R, et al. Incidence, risk factors and 90-day mortality of patients with acute kidney injury in Finnish intensive care units: the FINNAKI study. Intensive Care Med. 2013;39(3):420-8.

5. Kashani K, Al-Khafaji A, Ardiles T, Artigas A, Bagshaw SM, Bell M, Bihorac A, Birkhahn R, Cely CM, Chawla LS, et al. Discovery and validation of cell cycle arrest biomarkers in human acute kidney injury. Crit Care (London, England). 2013;17(1):R25.

6. Gocze I, Jauch D, Gotz M, Kennedy P, Jung B, Zeman F, Gnewuch C, Graf BM, Gnann W, Banas B, et al. Biomarker-guided intervention to prevent acute kidney injury after major surgery: the prospective randomized BigpAK study. Ann Surg. 2018;267(6):1013-20.

7. Meersch M, Schmidt C, Hoffmeier A, Van Aken H, Wempe C, Gerss J, Zarbock A. Prevention of cardiac surgery-associated AKI by implementing the KDIGO guidelines in high risk patients identified by biomarkers: the PrevAKI randomized controlled trial. Intensive Care Med. 2017;43(11):1551-61.

8. De Loor J, Decruyenaere J, Demeyere K, Nuytinck L, Hoste EA, Meyer E. Urinary chitinase 3-like protein 1 for early diagnosis of acute kidney injury: a prospective cohort study in adult critically ill patients. Crit care (London, England). 2016;20:38.

9. De Loor J, Herck I, Francois K, Van Wesemael A, Nuytinck L, Meyer E, Hoste EAJ. Diagnosis of cardiac surgery-associated acute kidney injury: differential roles of creatinine, chitinase 3-like protein 1 and neutrophil gelatinaseassociated lipocalin: a prospective cohort study. Ann Intensive Care. 2017; $7(1): 24$

10. von Elm E, Altman DG, Egger M, Pocock SJ, Gotzsche PC, Vandenbroucke $J P$, Initiative S. The Strengthening the Reporting of Observational Studies in 
Epidemiology (STROBE) statement: guidelines for reporting observationa studies. Lancet (London, England). 2007;370(9596):1453-7.

11. Bone RC, Balk RA, Cerra FB, Dellinger RP, Fein AM, Knaus WA, Schein RM, Sibbald WJ. Definitions for sepsis and organ failure and guidelines for the use of innovative therapies in sepsis. The ACCP/SCCM Consensus Conference Committee. American College of Chest Physicians/Society of Critical Care Medicine. Chest. 1992;101(6):1644-55.

12. Bellomo R, Ronco C, Kellum JA, Mehta RL, Palevsky P, Acute Dialysis Quality Initiative W. Acute renal failure - definition, outcome measures, animal models, fluid therapy and information technology needs: the Second International Consensus Conference of the Acute Dialysis Quality Initiative (ADQI) Group. Crit Care (London, England). 2004;8(4):R204-12.

13. DeLong ER, DeLong DM, Clarke-Pearson DL. Comparing the areas under two or more correlated receiver operating characteristic curves: a nonparametric approach. Biometrics. 1988;44(3):837-45.

14. Youden WJ. Index for rating diagnostic tests. Cancer. 1950;3(1):32-5.

15. Pines JMCC, Raja AS, Schuur JD. Evidence-based emergency care: diagnostic testing and clinical decision rules. Hoboken, New Jersey: Wiley; 2013.

16. Hoste EA, McCullough PA, Kashani K, Chawla LS, Joannidis M, Shaw AD, Feldkamp T, Uettwiller-Geiger DL, McCarthy P, Shi J, et al. Derivation and validation of cutoffs for clinical use of cell cycle arrest biomarkers. Nephrol Dial Transplant. 2014;29(11):2054-61.

17. Schmidt IM, Hall IE, Kale S, Lee S, He CH, Lee Y, Chupp GL, Moeckel GW, Lee CG, Elias JA, et al. Chitinase-like protein Brp-39/YKL-40 modulates the renal response to ischemic injury and predicts delayed allograft function. J Am Soc Nephrol. 2013;24(2):309-19.

18. Hall IE, Stern EP, Cantley LG, Elias JA, Parikh CR. Urine YKL-40 is associated with progressive acute kidney injury or death in hospitalized patients. BMC Nephrol. 2014;15:133.

19. Albeltagy ES, Abdul-Mohymen AM, Taha DRA. Early diagnosis of acute kidney injury by urinary YKL-40 in critically ill patients in ICU: a pilot study. Int Urol Nephrol. 2020;52:351-61.

20. Dela Cruz CS, Liu W, He CH, Jacoby A, Gornitzky A, Ma B, Flavell R, Lee CG, Elias JA. Chitinase 3-like-1 promotes Streptococcus pneumoniae killing and augments host tolerance to lung antibacterial responses. Cell Host Microbe. 2012;12(1):34-46.

21. He CH, Lee CG, Dela Cruz CS, Lee CM, Zhou Y, Ahangari F, Ma B, Herzog EL, Rosenberg SA, Li Y, et al. Chitinase 3-like 1 regulates cellular and tissue responses via IL-13 receptor alpha2. Cell Rep. 2013;4(4):830-41.

22. Lee CG, Dela Cruz CS, Herzog E, Rosenberg SM, Ahangari F, Elias JA. YKL-40, a chitinase-like protein at the intersection of inflammation and remodeling. Am J Respir Crit Care Med. 2012;185(7):692-4.

23. Bell M, Larsson A, Venge P, Bellomo R, Martensson J. Assessment of cellcycle arrest biomarkers to predict early and delayed acute kidney injury. Dis Markers. 2015;2015:158658.

24. Gayat E, Touchard C, Hollinger A, Vieillard-Baron A, Mebazaa A, Legrand M, investigators Fls. Back-to-back comparison of penKID with NephroCheck(R) to predict acute kidney injury at admission in intensive care unit: a brief report. Crit care (London, England). 2018;22(1):24.

25. Wetz AJ, Richardt EM, Wand S, Kunze N, Schotola H, Quintel M, Brauer A, Moerer O. Quantification of urinary TIMP-2 and IGFBP-7: an adequate diagnostic test to predict acute kidney injury after cardiac surgery? Crit Care (London, England). 2015;19:3.

26. Karlsson S, Varpula M, Ruokonen E, Pettila V, Parviainen I, Ala-Kokko TI, Kolho E, Rintala EM. Incidence, treatment, and outcome of severe sepsis in ICUtreated adults in Finland: the Finnsepsis study. Intensive Care Med. 2007; 33(3):435-43.

27. Rathcke CN, Persson F, Tarnow L, Rossing P, Vestergaard H. YKL-40, a marker of inflammation and endothelial dysfunction, is elevated in patients with type 1 diabetes and increases with levels of albuminuria. Diabetes Care. 2009:32(2):323-8.

28. Rathcke CN, Raymond I, Kistorp C, Hildebrandt P, Faber J, Vestergaard H. Low grade inflammation as measured by levels of YKL-40: association with an increased overall and cardiovascular mortality rate in an elderly population. Int J Cardiol. 2010;143(1):35-42.

29. Brix JM, Hollerl F, Koppensteiner R, Schernthaner G, Schernthaner GH. YKL40 in type 2 diabetic patients with different levels of albuminuria. Eur J Clin Investig. 2011:41(6):589-96.

30. Lee CG, Da Silva CA, Dela Cruz CS, Ahangari F, Ma B, Kang MJ, He CH, Takyar S, Elias JA. Role of chitin and chitinase/chitinase-like proteins in inflammation, tissue remodeling, and injury. Annu Rev Physiol. 2011;73:479-501.
31. Tong $X$, Wang D, Liu S, Ma Y, Li Z, Tian P, Fan H. The YKL-40 protein is a potential biomarker for COPD: a meta-analysis and systematic review. Int J Chron Obstruct Pulmon Dis. 2018;13:409-18.

32. Tong $X$, Wang D, Liu S, Ma Y, Fan H: Can YKL-40 be used as a biomarker and therapeutic target for adult asthma? Eur Respir J 2018, 51(1):1702194.

33. Kjaergaard AD, Johansen JS, Bojesen SE, Nordestgaard BG. Role of inflammatory marker YKL-40 in the diagnosis, prognosis and cause of cardiovascular and liver diseases. Crit Rev Clin Lab Sci. 2016;53(6):396-408.

34. Brew K, Dinakarpandian D, Nagase H. Tissue inhibitors of metalloproteinases: evolution, structure and function. Biochim Biophys Acta. 2000;1477(1-2): 267-83.

35. Johnson ACM, Zager RA. Mechanisms underlying increased TIMP2 and IGFBP7 urinary excretion in experimental AKI. J Am Soc Nephrol. 2018;29(8): 2157-67.

\section{Publisher's Note}

Springer Nature remains neutral with regard to jurisdictional claims in published maps and institutional affiliations.
Ready to submit your research? Choose BMC and benefit from:

- fast, convenient online submission

- thorough peer review by experienced researchers in your field

- rapid publication on acceptance

- support for research data, including large and complex data types

- gold Open Access which fosters wider collaboration and increased citations

- maximum visibility for your research: over $100 \mathrm{M}$ website views per year

At BMC, research is always in progress.

Learn more biomedcentral.com/submissions 